\title{
Co-Chief-Editor's Address
}

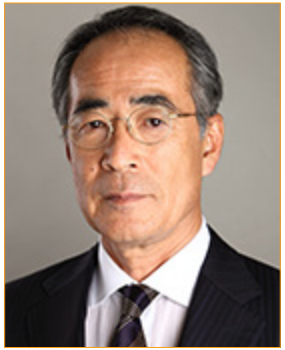

Kotaro Maeda

Co-Chief-Editor

of Annals of Coloproctology

Secretary General of APFCP

\section{Annals of Coloproctology to be an Official Journal of APFCP}

Asian Pacific Federation of Coloproctology (APFCP) would like to congratulate that Annals of Coloproctology (ACP) became an official Journal of APFCP and will be published on April 2020 as an official Journal of APFCP. This decision was made by the Council meeting of APFCP at the 17th Biennial Congress of APFCP held in Malaysia on 15th March 2019, and the agreement was tied to approve Korean Society of Coloproctology's (KSCP's) academic Journal "Annals of Coloproctology" as an official Journal of APFCP, through mutual cooperation between Korean Society of Coloproctology (KSCP) and APFCP on 5th April, 2019 in Jeju, Korea. APFCP would like to express sincere appreciation to KSCP for contribution to APFCP's official Journal in many aspects, especially to APFCP's past President Ho-Kyung Chun, KSCP President Jun Gu Kang and KSCP's past President Woo Yong Lee for their contribution to ACP be an official Journal of APFCP. 